\title{
PERCEPÇÃO SOCIOAMBIENTAL DOS ALUNOS DE ENSINO FUNDAMENTAL DE UMA ESCOLA MUNICIPAL DE CAXINGÓ, PIAUÍ, BRASIL
}

\author{
F. C. F. CRUZ, M. F. S. SILVA* \& I. M. ANDRADE \\ Universidade Federal do Ceará \\ lenolysilva@hotmail.com*
}

Artigo submetido em agosto/2014 e aceito em agosto/2016

DOI: $10.15628 /$ holos.2016.2352

\section{RESUMO}

A Educação Ambiental é um elemento eficaz no instrumento da formação de cidadãos responsáveis pela construção e manutenção do meio ambiente equilibrado. A percepção ambiental está intimamente ligada à cultura, história, experiência e tempo de cada indivíduo. Diante da importância da educação ambiental para a formação dos alunos e pretendendo sanar a falta de informações sobre os principais problemas socioambientais e as consequências que o ambiente e as futuras gerações podem sofrer, objetivou-se com este estudo analisar a percepção ambiental dos alunos do ensino fundamental em uma escola municipal de Caxingó, Piauí, e verificar como estes compreendem o significado de meio ambiente e reconhecem os problemas ambientais locais. A metodologia foi do tipo quanti-qualitativa e descritiva. Foi aplicado questionário a 129 alunos alunos, do $6^{\circ}$ ao $9^{\circ}$ do ensino fundamental, com faixa etária entre 10 e 19 anos. Pode-se perceber a percepção dos alunos sobre o ambiente é, reforçando a necessidade do desenvolvimento de projetos e/ou programas de Educação Ambiental no cotidiano da escola.

PALAVRAS-CHAVE: Educação Ambiental, Meio Ambiente, Problemas Ambientais.

\section{ENVIRONMENTAL PERCEPTIONS OF ELEMENTARY STUDENTS AT A MUNICIPAL SCHOOL IN CAXINGÓ, PIAUII, BRAZIL}

\begin{abstract}
Environmental Education is an effective tool for the formation of citizens responsible for building and maintaining a balanced environment. Environmental perception is closely linked to culture, history, and contemporary experience of each individual. Environmental education is important of for student's general education and there is a need to redress the lack of information on key environmental problems and the impact that the environment can have on future generations. The aim of this study is therefore to analyze the environmental perception of elementary school students a public school in the municipality of Caxingó,
\end{abstract}

Piauí, and to verify how they comprehend the significance of the environment and recognize local environmental problems. The methodology was qualitative-quantitative and descriptive. We conducted a questionnaire with students from the 6th to the 9th grade in elementary school. 129 students were questioned, aged from 10 to 19 years old. The results showed a generally poor development of environmental awareness in students, reinforcing the need for further development of environmental education in the daily studies of students at school.

KEYWORDS: Environmental education, Environment, Environmental Problems. 


\section{INTRODUÇÃO}

A Educação Ambiental é um instrumento eficaz na formação de cidadãos responsáveis pela construção e manutenção do meio ambiente equilibrado. Seu significado está relacionado ao aprendizado e ao emprego de novas tecnologias, aumento de produtividade, redução de danos ambientais, conhececimento e utilização de novas oportunidades, além de tomar decisões acertadas (EFFTING, 2007).

Estudos que se baseiam na percepção ambiental propõem que não só a relação entre homem e meio ambiente seja estudada, mas que perspectivas em pesquisas científicas, sociais ou políticas sejam elucidadas através da utilização deste conceito (PACHECO; SILVA, 2006). Estudo da percepção ambiental é de fundamental importância, pois possibilita o conhecimento de cada um dos grupos envolvidos, facilitando a realização de um trabalho com bases locais, ou seja, partindo da realidade do público alvo é possível conhecer como os indivíduos percebem o ambiente em que vivem, suas fontes de satisfação e insatisfação (FAGGIONATO, 2007).

A percepção ambiental está intimamente ligada à cultura, história, experiência e tempo de cada indivíduo. Para que se possa perceber algo de fato, é necessário que se tenha algum tipo de interesse pelo objeto de percepção. Os paradigmas e os conhecimentos de cada um são bases fundamentais do interesse e permitem que cada ser humano possua uma percepção única para o mesmo objeto (PALMA, 2005).

Ferreira (1997) reconhece dois tipos de percepção: a percepção visual, que são as atitudes que não consideram as consequências, e a percepção informacional, que são as ações refletidas. Perceber significa decifrar ou reconhecer a mensagem sensorial, é enxergar uma árvore como o ambiente, visualizar um incêndio na floresta como um sinal de alarme aos seres ali existentes. Perceber é diferente de sentir, este exige apenas detectores ou sensores; o perceber exige, além desses, órgãos capazes de interpretar aquilo que é sentido ou captado.

É de fundamental importância identificar a forma como os seres humanos percebem o ambiente em que vivem para entender a relação que os mesmos desenvolvem com o meio. Diante deste conhecimento é possível planejar ações duradouras para a problemática ambiental, pois os problemas ambientais são fundamentalmente problemas humanos, e este quer sejam econômicos, políticos ou sociais, dependem do centro psicológico da motivação, dos valores e atitudes dos seres humanos (TUAN, 1980).

No decorrer do século passado e conseqüentemente no século atual, para que as necessidades humanas fossem atendidas foi se desenhando uma equação desbalanceada, retirar, consumir e descartar (EFFTING, 2007). Entretanto, a natureza deve ser pensada como movimento permanente de auto-organização e criação do universo e, portanto, da vida (LOUREIRO, 2007). A realidade atual exige uma reflexão cada vez menos linear, e isto se produz na inter-relação dos saberes e das práticas coletivas que criam identidades e valores comuns e ações solidárias diante da reapropriação da natureza, numa perspectiva que privilegia o diálogo entre saberes (JACOBI, 2003).

Estudos que se baseiam na percepção ambiental propõem que não só a relação entre homem e meio ambiente seja estudada, mas também que perspectivas em pesquisas científicas, sociais ou políticas sejam elucidadas através da utilização deste conceito (PACHECO; SILVA, 2006). 
A Educação Ambiental foi considerada inicialmente como uma preocupação dos movimentos ecológicos com a prática de conscientização capaz de chamar a atenção para a má distribuição do acesso aos recursos naturais, assim como ao seu esgotamento, e envolver os cidadãos em ações sociais ambientalmente apropriadas (CARVALHO, 2006). Uma prática que tem se mostrado efetiva é a de o termo meio ambiente estar sendo utilizado em meios de comunicação e em discursos políticos, livros didáticos, músicas e outras fontes, embora haja uma grande diversidade conceitual, possibilitando diferentes interpretações, muitas vezes, influenciadas pela vivência pessoal, profissional e pelas informações veiculadas na mídia (BEZERRA; GONÇALVES, 2007).

A Educação Ambiental é um processo pelo meio do qual as pessoas aprendem como funciona o ambiente, como dependemos dele, como afetamos e promovemos a sua sustentabilidade (DIAS, 2003). Segundo Borges e Matos (1990), a conservação do meio ambiente somente será alcançada através de um processo de conscientização ecológica, isto é, através da educação das populações. Esta educação deve reorientar as atividades sócias visando a melhoria da qualidade de vida e do meio ambiente.

O caráter principal da Educação Ambiental não é solucionar os complexos problemas ambientais decorrentes das intervenções antrópicas, mas, formar cidadãos aptos a lutar pelos seus direitos, conscientes de seus deveres e capazes de agir tanto de forma preventiva como mitigadora dos possíveis impactos ambientais negativos que possam gerar (LORENZI, 2003).

Educação ambiental, ao educar para a cidadania, pode construir a possibilidade da ação política no sentido de contribuir para formar uma coletividade que é responsável pelo mundo que habita (SORRETINO et al., 2005). Educação Ambiental significa aprender a empregar novas tecnologias, aumentar a produtividade, evitar desastres ambientais, diminuir os danos existentes, conhecer e utilizar novas oportunidades e tomar decisões acertadas (EFFTING, 2007).

No ensino formal, o Ministério da Educação (MEC), atualmente utiliza o sistema da transversalidade para a melhoria do ensino. Infelizmente, não são todos os educadores que conhecem perfeitamente a proposta da transversalidade e poucos são os que, juntamente com sua escola, a aplicam (GALLO, 2001). Ainda existe falta de incentivo e muitas vezes conhecimento dos próprios professores nessa área (SARAIVA et al., 2008).

Diante da importância que a Educação Ambiental tem para a formação dos alunos, objetivou-se com este estudo analisar a percepção ambiental dos alunos do ensino fundamental de uma escola municipal do município de Caxingó, Piauí e verificar como estes compreendem o significado de meio ambiente e reconhecem os problemas ambientais locais.

\section{METODOLOGIA}

\subsection{Tipo de pesquisa}

O estudo foi do tipo quanti-qualitativo e descritivo, com aplicação de questionário aplicado aos alunos do $6^{\circ}$ ao $9^{\circ}$ do ensino fundamental da Unidade Escola Felipe Neris Machado, Caxingó, Piauí.

Na metodologia quantitativa, leva-se em conta amostras e informações numéricas para medir opinião e atitudes. Já o enfoque qualitativo é utilizado na observação simples do ambiente 
pesquisado e na análise dos depoimentos dos entrevistados, pautando-se na técnica de análise de conteúdo. Não se preocupa com representatividade numérica, mas sim com o aprofundamento da compreensão de um grupo social, de uma organização etc. O conhecimento do pesquisador é parcial e limitado (MARCONI; LAKATOS, 2011).

Na pesquisa descritiva, observa, registra, analisa e correlaciona fatos ou fenômenos sem manipular variáveis. A fonte direta de dados é o ambiente, pois procura-se descobrir a frequência com que um fenômeno ocorre, sua relação e conexão com outros fenômenos, sua natureza e características. Trabalha sobre dados ou fatos colhidos da própria realidade. Não interfere na realidade, apenas descreve e interpreta os fatos que influenciam o fenômeno estudado, estabelecendo correlação entre variáveis. Deve ter fundamentação teórica e prática (PORTELA, 2004; MARCONI; LAKATOS, 2011).

\subsection{Local do desenvolvimento da pesquisa}

O município de Caxingó está localizado na microrregião do litoral piauiense, ao norte do estado, a uma distância aproximada de $270 \mathrm{~km}$ de Teresina, capital do Estado. Limita-se ao norte e a Leste com município de Buriti dos Lopes, ao Sul com Joaquim Pires e Caraúbas e a Oeste com Murici dos Portelas (SEMEC, 2013) (Fig. 01). Possui população de 5.213 habitantes, com área territorial de 488,169 $\mathrm{km}^{2}$ (IBGE, 2013).

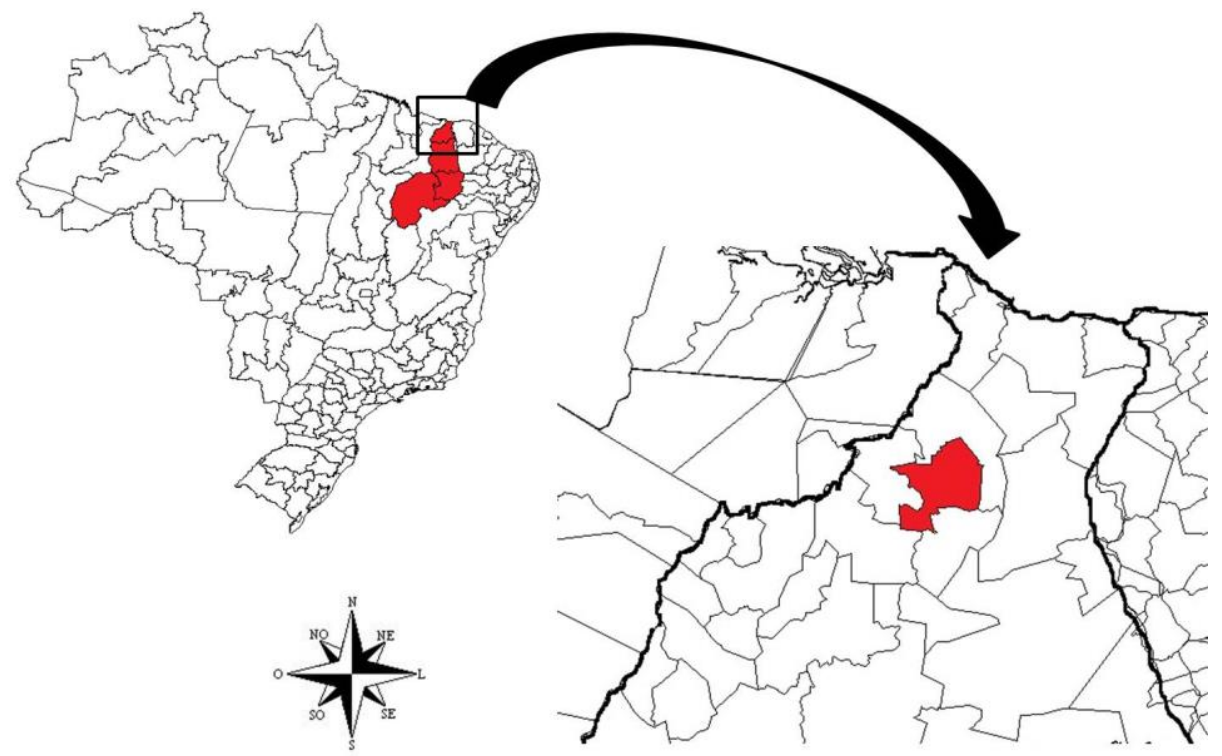

Figura 01. Localização do Munícipio de Caxingó, Piauí.

O município de Caxingó tem 28 escolas municipais e uma estadual, sendo 25 de Ensino Fundamental I e 03 de Ensino Fundamental I e II, 01 de Educação Infantil e 01 do Ensino Médio, distribuídas na zona urbana e rural do município (SEMEC, 2013).

A pesquisa foi realizada em uma escola da rede pública municipal de Caxingó, na zona urbana do município, Unidade Escolar Felipe Neris Machado.

A Unidade Escola Felipe Neris Machado vem atendendo o alunado desde a década de 60, está localiza na Rua Felipe Neris Filho, s/n no bairro centro e dispõe de infraestrutura em bom estado de conservação, contendo: diretoria, secretaria, sala de professores, laboratório de informática, biblioteca, refeitório, oito salas de aula e três banheiros. Esta estrutura atende o 
Ensino Fundamental menor, maior e Educação de Jovens e Adultos (EJA) nos turnos matutino, vespertino e noturno. A escola possui em seu quadro de funcionários 33 profissionais: um diretor, um secretário, nove professores do Ensino Fundamental menor, 13 professores do Ensino Fundamental maior, um coordenador pedagógico, sete auxiliares de serviços gerais e um porteiro. O Índice de Desenvolvimento da Educação Básica (IDEB) da escola está abaixo do valor de referência, 3,8, sendo necessária uma análise criteriosa dos dados, planejamento e execução de intervenções pedagógicas para que este quadro seja invertido.

A pesquisa foi realizada no período de maio a novembro de 2013 , através de aplicação de questionário composto por 17 perguntas fechadas, visando identificar a faixa etária, a predominância do sexo e os conhecimentos em relação à Educação Ambiental e avaliar os problemas socioambientais locais.

Participaram da amostra os alunos do $6^{\circ}$ ao $9^{\circ}$ ano, do turno vespertino, totalizando 129 alunos.

\subsection{Análise dos dados}

Apresentar-se-á uma análise descritiva (exploratória) para mensuração e classificação de variáveis disponíveis: qualitativas e quantitativas. Os gráficos foram elaborados no programa Microsoft Office Excel 2010

\section{RESULTADOS E DISCUSSÕES}

Dos 129 alunos entrevistados $51,9 \%$ são do sexo feminino e $48,1 \%$ do sexo masculino. A idade variou de 10 a 13 anos (30\%), 14 a 16 (56\%) e de 17 a 19 anos (14\%) (Fig. 02). Pode-se perceber que há distorção de idade-série, pois o adequado seria concluir o ensino fundamental com 14 ou 15 anos de idade.

A taxa de distorção idade-série, que revela o nível do desempenho escolar e capacidade do sistema educacional manter a frequência do aluno em sala de aula, é um forte indício da condição da educação básica na zona rural. Enquanto a falta de sincronismo idade-série é um problema ainda a ser superado na educação básica do País, o quadro na zona rural se mostra ainda mais grave. No Nordeste as séries iniciais do ensino fundamental apresentam uma elevada distorção idade-série de $54 \%$ dos seus alunos com idade superior à prevista para estas séries. Esse problema repercute como uma onda nas demais séries, fazendo com que esses alunos cheguem às séries finais do ensino fundamental com uma defasagem ainda maior, de 75,2\% (FURTADO, 2004).

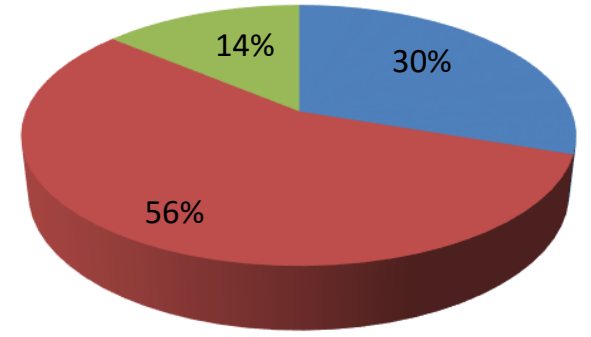

$$
\begin{array}{r}
10 \text { a } 13 \text { anos } \\
-14 \text { a } 16 \text { anos } \\
17 \text { a } 19 \text { anos }
\end{array}
$$

Figura 02. Faixa etária dos 129 alunos da Unidade Escolar Felipe Neris Machado, Caxingó, PI. (Fonte: CRUZ, 2014). 
As questões abordadas, trataram do perfil sócio econômico dos alunos e temas para verificar a percepção ambiental, conforme apresentadas a seguir.

Questão 01- Buscou saber a local de moradia dos alunos, se zona rural ou urbana. A maioria $(94,6 \%)$ responderam que moram na zona rural e $5,4 \%$ na zona urbana.

É sabido que os estudantes da zona rural encontram grandes obstáculos no processo formativo que vão desde o deslocamento, por meio de transporte escolar, até questões culturais mais amplas. A diferença entre os alunos da zona rural e urbana quanto ao sistema educacional é notória. Atualmente $26,5 \%$ da população rural com idade de mais de 10 anos tem menos de um ano de estudo, enquanto em zonas urbanas esse percentual é de 10,2\% (DOURADO, 2005).

Questão 02 e 03- Tratou de moradia de cada aluno. A maioria (92,2\%) respondeu morar em casa própria, 3,9\% cedidas, $0,8 \%$ alugadas e 3,1\% vivem em outros tipos de moradia (Fig. 03). E quanto ao tipo de construção das casas dos alunos: $46,5 \%$ possuem casa do tipo alvenaria, $26 \%$ mista, $22,5 \%$ são de madeira e $5 \%$ são construídas de outros materiais.

Questão 04- Se os alunos têm em sua residência energia elétrica. A maioria é beneficiado com energia elétrica em suas residências (97,7\%), enquanto $2,3 \%$ não disponibiliza deste recurso.

No senso do IBGE (2000), 59,1\% da população do município de Caxingó dispunha de energia elétrica, enquanto $40,9 \%$ não possuíam este tipo de serviço, entretanto, atualmente, pode-se encontrar energia elétrica em quase todo o município de Caxingó devido ao programa luz para todos, criado pelo governo federal em 2003, que tornou acessível energia elétrica para várias famílias. Antes do município ser emancipado poucos lugares da zona rural possuíam eletricidade.

A humanidade está cada vez mais dependente da energia elétrica para processar suas atividades. Para Dias (2003), essa dependência crescente poderá levá-la a crises e situações imprevisíveis, caso os recursos ambientais de que dispomos, não sejam utilizados de forma sustentada.

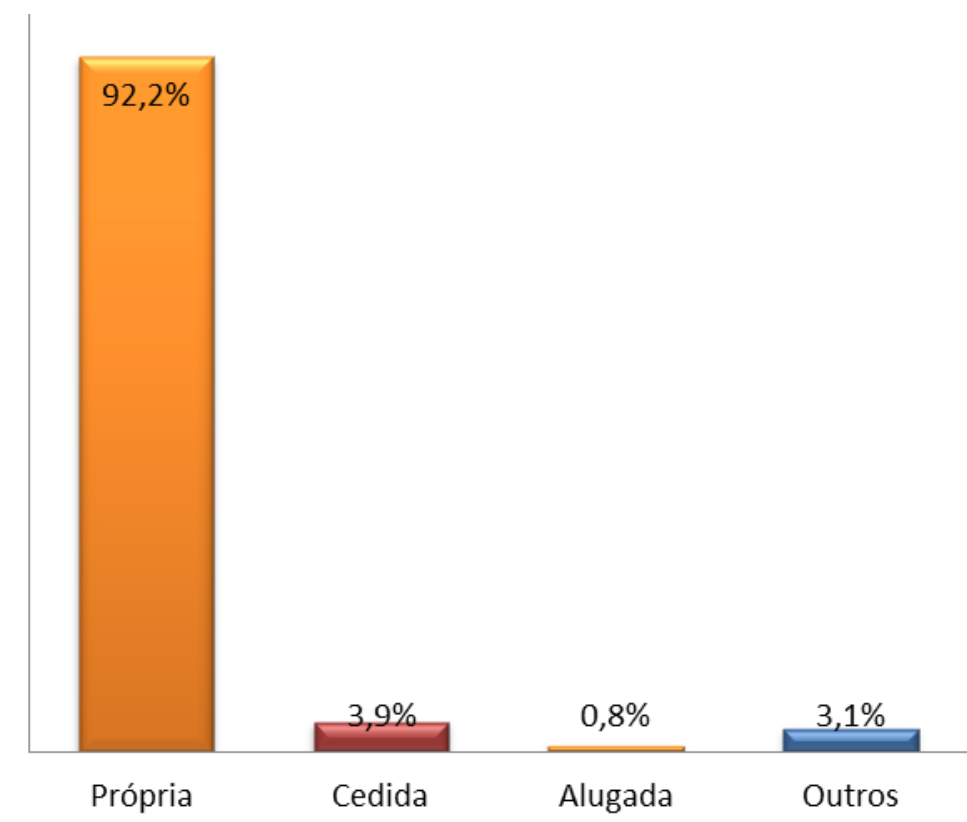

Figura 03- Moradia dos alunos da Unidade Escolar Felipe Neris Machado, Caxingó, PI. (Fonte: CRUZ, 2014). 
Questão 05- Quanto ao de abastecimento de água nas residências dos alunos, a maioria $(60,5 \%)$ utiliza o abastecimento de água através de poços, enquanto os demais utilizam de rios $4,5 \%$, açudes $2,5 \%$, chafarizes $22,5 \%$ e $10 \%$ utilizam água encanada (Fig. 04 ).

O município ainda não dispõe de uma rede de tratamento de água para o consumo da população. A utilização de uma rede de tratamento de água é de grande importância, pois retira as impurezas ou algum tipo de poluente que possa estar contida na água que possa ser prejudicial à saúde da população em geral.

No município de Caxingó, a distribuição dos domicílios segundo as formas de abastecimento de água, $14,7 \%$ utiliza de rede geral da distribuidora, $63,8 \%$ poço ou nascente e $21,5 \%$ de outros tipos de abastecimento (IBGE, 2000).

Segundo o Censo Demográfico de 2000, do IBGE, nas zonas urbanas do Brasil, a cobertura dos serviços de água atinge $71,2 \%$ das famílias com renda de até dois salários mínimos, ou sem rendimento, e chega a 98,6 \% na classe de mais de 10 salários mínimos. No Piauí, confirmando a regra, mas destacando a disparidade de renda do Estado em relação ao País, esses índices são de $40 \%$ e $96,7 \%$, respectivamente, indicando ainda que, em qualquer parte, aqueles que tem o poder aquisitivo econômico maior tem acesso semelhante, enquanto os menos favorecidos, com a mesma faixa de renda, encontram-se, em maior número, são excluídos desse benefício (OLIVEIRA; MONTEIRO, 2005).

O Estado do Piauí possui água em abundância na maior parte do seu território, porém ainda apresenta 1.523.300 pessoas sem água canalizada em domicílio, conforme o Censo Demográfico de 2000 , ou seja, $53,8 \%$ da sua população total, dos quais 558.600 são residentes nas zonas urbanas, ou seja, 31,4\% da população total que vive nas cidades (OLIVEIRA; MONTEIRO, 2005).

O número de domicílios particulares permanentes que têm acesso ao fornecimento de água no Brasil passou de 45 milhões para pouco mais de 57 milhões nos últimos dez anos, de acordo com os resultados preliminares do Censo Demográfico 2010. A distribuição de água no país cresceu aproximadamente $22 \%$ em relação ao Censo Demográfico de 2000 . Com isso, cerca de 12,5 milhões de residências passaram a utilizar tal serviço, das quais a maioria pela rede geral de distribuição. 0 sistema padrão de fornecimento, que tinha cerca de 35 milhões de domicílios há dez anos, concentra atualmente aproximadamente 47 milhões e meio de consumidores no país (ANDRADE, 2011).

O índice de brasileiros que necessitam de poços ou nascentes foi reduzido em quase um milhão e meio de pessoas, uma queda de aproximadamente $18 \%$. A rede geral de distribuição de água está avançando pelo território. Em 2000, quase sete milhões de brasileiros utilizavam poços e/ou nascentes. Dez anos depois, esse número é de pouco mais de cinco milhões e meio. As regiões que apresentaram queda foram Nordeste e Sudeste. Tais regiões impulsionaram o crescimento geral da distribuição de água (ANDRADE, 2011). 


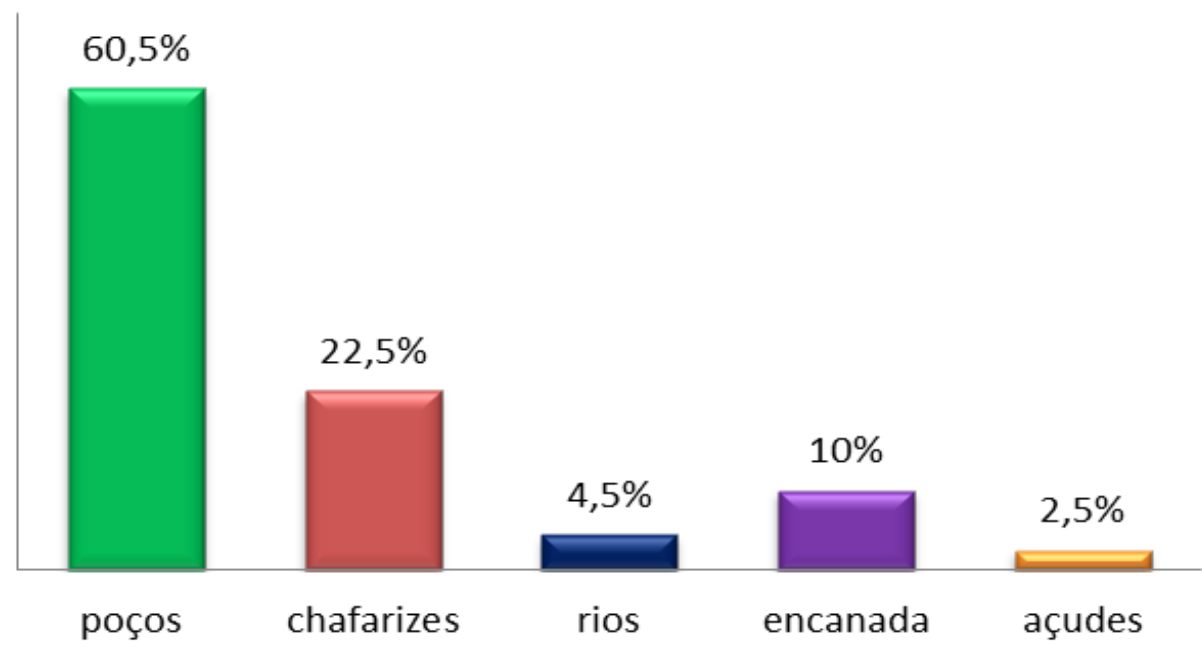

Figura 04- Forma de abastecimento de água nas residências dos alunos da Unidade Escolar Felipe Neris Machado, Caxingó, PI. (Fonte: CRUZ, 2014).

Questão 06- Quanto a existência de saneamento básico, a maioria $(65,9 \%)$ respondeu que não existe. Diante das respostas percebe-se que os alunos não sabem o significado de saneamento básico, pois o município não dispõe deste tipo de serviço.

Segundo o IBGE (2010), apenas três dos municípios do Piauí, equivalente a 1\%, tem algum órgão responsável pelo saneamento básico municipal, ou seja, $99 \%$ não têm políticas voltadas para o setor, enquanto a média nacional é de $30 \%$ e no Nordeste $19 \%$. O IBGE também revelou que apenas dois $(0,89 \%)$ dos municípios do Piauí declararam ter programa para coleta de lixo.

Quanto maior o aglomerado humano maiores os problemas para a manutenção da higiene do ambiente. Nas regiões indústrias, nos portos, nas regiões de garimpo, aumenta a variedade de dejetos lançados no ambiente. É necessário, portanto, que as trocas com o ambiente sejam feitas de modo a garantir a sua preservação (BRASIL, 1997).

Questão 07- Tratou dos problemas ambientais existentes na região onde cada aluno reside. Os problemas mais listados foram: queimadas ( $86 \%)$, poluição do ar (4,5\%), poluição de rios e lagos $(4,5 \%)$, enchentes (1,5\%), falta de rede de esgoto (1,5\%) e 1,5\% não responderam (Fig. 05).

A problemática ambiental emerge da história das relações dos homens com a natureza, sob os aspectos econômicos, políticos e sociais, reafirmando a abordagem socioambiental conferida a essa problemática (TOZONI-REIS, 2008).

Santos (2007) investigando sobre os problemas ambientais enfrentados na percepção de alunos de escolas públicas do município de Santa Maria, no estado do Rio Grande do Sul registrou que a maioria (58\%) respondeu ser o acúmulo de lixo o maior problema, seguido por poluição do ar (13\%), $12 \%$ poluição das águas, $13 \%$ falta de orientação sobre os riscos que os resíduos sólidos causam à saúde e $5 \%$ buzina sem necessidade.

Machado et al. (2010), por sua vez, averiguou resultados semelhantes aos registrados neste trabalho, ou seja, queimadas (24\%), acompanhado de acúmulo de lixo (22\%), desmatamentos (19\%), desperdício de água e energia (19\%), poluição geral (14\%) e $2 \%$ não souberam responder. Esses dados possibilitaram inferir sobre a necessidade de empregar técnicas pedagógicas sobre educação ambiental para transformar a realidade local. Já Andrades (2010), investigando se a flora nativa do município de Parnaíba estava sendo destruída, registrou que a destruição é feita pela 
ação do homem. As principais causas para a destruição da flora é o desmatamento (43\%) e as queimadas (28\%).

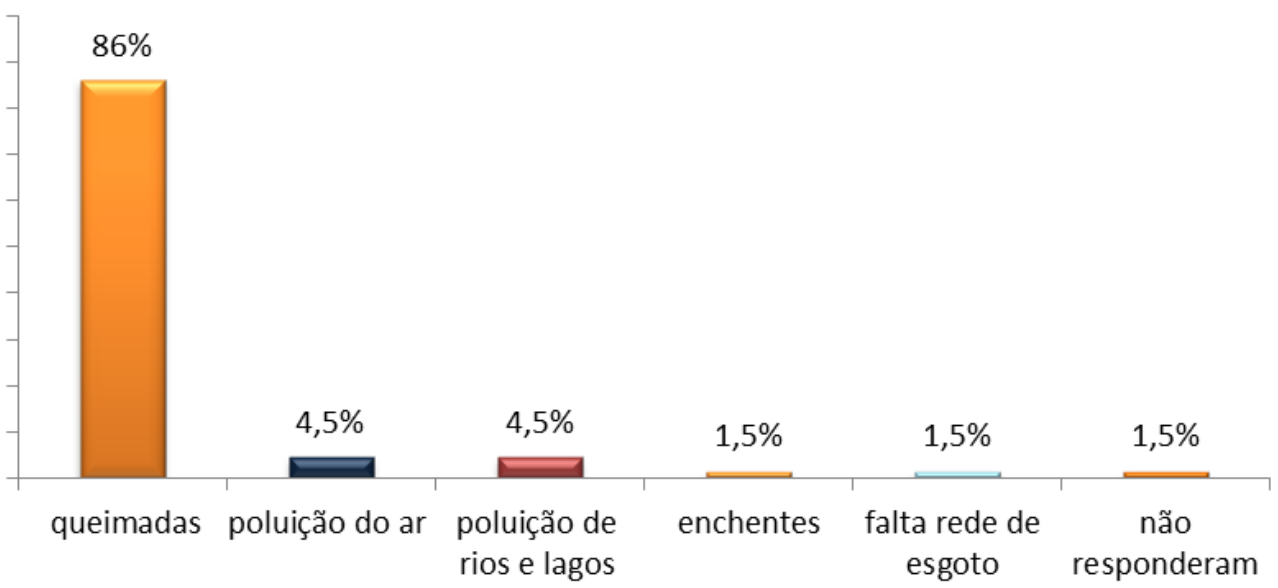

Figura 5- Percepção dos alunos da Unidade Escolar Felipe Neris Machado sobre problemas ambientais, Caxingó, PI. (Fonte: CRUZ, 2014).

Questões 08 e 09- Quanto à ocorrência de desmatamento e queimadas na região onde os alunos residem, a maioria $(88,4 \%)$ respondeu que há desmatamento. Com relação as queimadas, $85,3 \%$ responderam que são afetados com esse problema constantemente (Fig. 6). As porcentagens entre desmatamento e queimadas são semelhantes porque o uso de madeira é bastante comum na região e as queimadas são realizadas anualmente para uso da terra no cultivo de produtos agrícolas, como arroz, feijão, milho e mandioca utilizados pela população como atividades de subsistência, além da retira madeira para construções de casas, cercas e móveis.

As queimadas, também apontadas pelos alunos como atividade grave que ocorre na região, é um dos principais problemas enfrentados pela população, também pode ocorrer acidentalmente, afetando grandes extensões de terra e prejudicando a fauna e a flora da região.

Entende-se por queimada o emprego de fogo em práticas agropastoris e florestais. É um método arcaico de limpar o solo, causando além da destruição e empobrecimento do solo, prejuízos a saúde humana. O decreto n. 2.661, de 8 de julho de 1998, proibe o emprego de fogo nas florestas e demais formas de vegetação, embora permita a queima controlada em práticas agropastoris e florestais, a permissão será estabelecida em ato do Poder Público, circunscrevendo as áreas e estabelecendo normas de precaução (SIRVINSKAS, 2003).

$\mathrm{Na}$ atividade agrícola faz-se necessário a correção do solo e a utilização de adubos para o plantio. O manejo incorreto do solo, abandonos de culturas, queimadas, desmatamento em larga escala, prática de monocultura e plantio fora da curva de nível acarreta a perda de fertilidade e condições propícias para a erosão (BRASIL, 1997). 


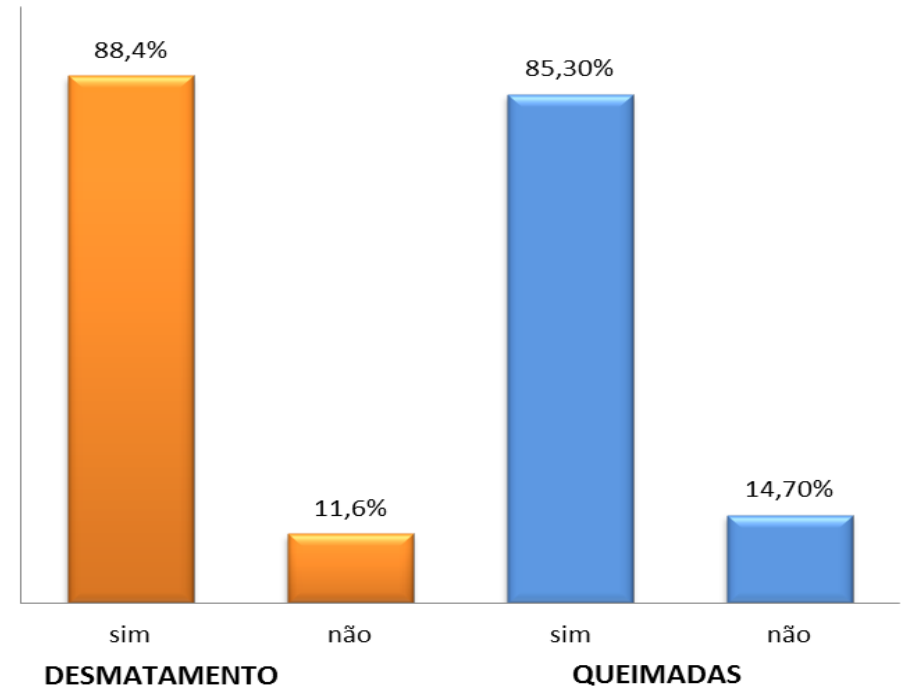

Figura 6 - Porcentagem de ocorrência de desmatamento e queimadas nas localidades onde moram os alunos da escola Unidade Escolar Felipe Neris Machado, Caxingó, PI. (Fonte: CRUZ, 2014).

Questão 10- Buscou saber qual o nível de entendimento dos alunos sobre assuntos relacionados ao meio ambiente, tais como, aquecimento global, poluição, mudanças climáticas, escassez de água entre outros. $62,7 \%$ dos alunos tem pouco entendimento sobre o tema, $22,5 \%$ sabem muito e $14,7 \%$ não conhecem o tema (Fig. 7).

Segundo Machado et al. (2010), os alunos que não se aproximam do objeto de estudo (meio ambiente) são impossibilitados no engajamento de diversas ações surgidas na vida moderna e não terão atitude crítica de sua realidade.

Os alunos mostraram-se pouco informados a respeito de assuntos que afetam o meio ambiente, seja direta ou indiretamente. Além disto, falta interesse ou incentivo em conhecer ou se aprofundar no tema.

Atualmente existem muitos meios de informações que tratam de assuntos relacionados ao meio ambiente. Dificilmente podemos encontrar um lugar em que as pessoas não estejam cientes dos grandes problemas ambientais. Acredita-se que a falta de informação pode ser devido a falta de interesse dos alunos pelo ambiente.

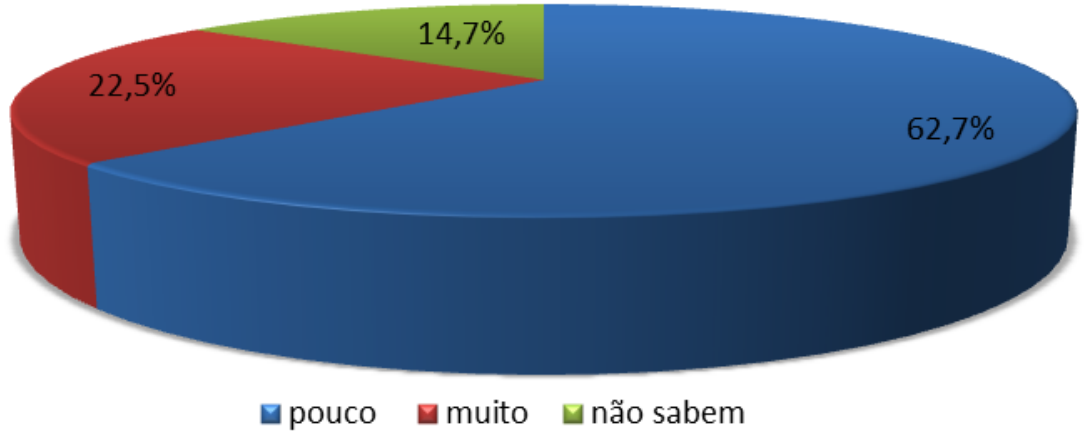

Figura 7- Entendimento dos alunos da Unidade Escolar Felipe Neris Machado, Caxingó, PI, sobre meio ambiente.

(Fonte, CRUZ, 2014).

Questão 11- Sobre a existência de programa de Educação Ambiental na escola observouse que a maioria $(86,8 \%)$ dos questionados respondeu que não há programa de Educação 
Ambiental em sua escola, enquanto $(13,2 \%)$ desconhece. Percebe-se que há controvérsia nas respostas dos alunos, talvez porque não tenham conhecimento se realmente a escola disponibilize ou não programas que abordem essa temática.

Programar a Educação Ambiental nas escolas tem se mostrado uma tarefa exaustiva. Existem grandes dificuldades nas atividades de sensibilização e formação na implantação de atividades e projetos e, principalmente, na manutenção e continuidade dos já existentes (EFFTING, 2007).

Para alguns autores como Rocha (2010), somente será possível mudar a atual situação do meio ambiente quando for inserido o tema Educação Ambiental desde a educação infantil, pois assim estaremos preparando cidadãos para ter uma postura de respeito à natureza. Lopes et al. (2009) comenta que atividades quem envolvam praticas de Educação Ambiental somente ocorre em datas comemorativas, ou seja, não há processo contínuo de conscientização no ambiente escolar. Acredita-se que quando o homem desde cedo tem conhecimento das questões ambientais, a possibilidade de obter respeito será maior.

Saraiva et al. (2008), em seu trabalho realizado com professores de escolas públicas do município de João Câmara, Rio Grande do Norte, mostraram que, apesar de 31\% dos professores afirmarem que a escola desenvolve programa de Educação Ambiental com seus alunos, a maioria (69\%) desconhece que há programas voltados para Educação Ambiental. Devido à proximidade das respostas, não é possível concluir se a escola possui ou não esses programas.

A Constituição Federal, Lei no. 9.795/99, Art. 1ำ, coloca que a Educação Ambiental tem que ser promovida em todos os níveis: educação básica - educação infantil e ensinos fundamental e médio; educação superior; educação especial; educação profissional e educação de jovens e adultos. A dimensão ambiental deve constar também nos currículos de formação de professores, em todos os níveis e em todas as disciplinas.

Questão12- Sobre a existência de problemas ambientais na escola, a maioria dos alunos $(62,8 \%)$ respondeu que há problemas. Da mesma forma que a questão anterior, não é possível saber se existem ou não problemas na escola. A percepção que os alunos possuem do ambiente escolar mostra que os mesmos são alheios aos problemas ocorrentes em local onde passam várias horas do seu dia.

A Educação Ambiental, como componente essencial no processo de formação e educação permanente, e com uma abordagem direcionada para a resolução de problemas, contribui para o envolvimento ativo do público, tornando o sistema educativo mais relevante e mais realista, além de estabelecer uma maior interdependência entre estes sistemas e o ambiente natural e social (EFFTING, 2007).

Percebe-se que há uma grande necessidade de programas de Educação Ambiental na escola para tornar os alunos mais conscientes dos problemas que afetam a região. Implantar a Educação Ambiental na grade curricular nas séries finais do ensino fundamental é de grande importância para a formação e aperfeiçoamento das práticas educativas voltadas à preservação do meio ambiente. Entretanto, a escola em estudo não está inserida neste contexto.

Questão 13 - Sobre o destino do lixo produzido em casa. A maioria dos questionados $(80,6 \%)$ queimam o lixo, 6,9 \% enterram, 8,5\% reciclam e 3,5\% não utilizam nenhuma das alternativas citadas (Fig. 8). Esse alto índice de queima deve ser ocasionados pela falta de um 
destino adequado para esses resíduos e/ou falta programas de educação ambiental que mostrem maneiras adequadas de como devemos tratar os resíduos produzidos em nossas residências.

Segundo IBGE (2000), em Caxingó a distribuição dos domicílios com relação ao destino dado ao lixo, $13,6 \%$ coletam o lixo e $86,4 \%$ dão outro destino ao lixo.

O Plano Nacional de Resíduos Sólidos - PNRS (2011) diagnosticou 2.906 lixões no Brasil, distribuídos em 2.810 municípios, que devem ser erradicados. Em números absolutos, o estado da Bahia é o que apresenta mais municípios com presença de lixões (360), seguido pelo Piauí (218), Minas Gerais (217) e Maranhão (207). Outra informação relevante é de que $98 \%$ dos lixões existentes concentram-se nos municípios de pequeno porte e $57 \%$ estão no Nordeste.

De acordo com Dias (2003), a questão do lixo produzido nas cidades é, sem dúvida, um dos grandes problemas na maioria dos municípios brasileiros. Os altos custos de implantação dos sistemas de coleta e tratamento de lixo têm levado ao fracasso muitas tentativas dos órgãos governamentais resolverem o problema.

Questão 14 e 15 - Procuraram identificar a existência de coleta seletiva na cidade e a coleta de lixo no local onde os alunos residem. Verificou-se que $39,5 \%$ dos alunos dizem que existe coleta seletiva na cidade e $60,5 \%$ respondeu que não existe coleta seletiva; 39,5\% afirmaram que passa carro coletando lixo na rua ou localidade e $60,5 \%$ afirma que não passa carro de coleta de lixo na rua ou localidade (Fig. 9).

A coleta de lixo é um procedimento paliativo, pois na cidade não há local adequado para seu destino final. Em presença das respostas obtidas pode-se perceber que a maior parte dos alunos não compreende a significação de coleta seletiva.

Coleta seletiva são serviços de infraestruturas e instalações operacionais de fornecimento de água potável, esgotamento sanitário, limpeza urbana, manejo de resíduos sólidos e manobro de água pluvial e drenagem (PNRS, 2012).

O aumento de lixo cresce desordenadamente a cada ano devido ao consumo e crescimento acelerado das cidades, sem haver medidas de controle para amenizar ou solucionar parte desse problema, que vem se agravando cada vez mais e que estão prejudicando o meio ambiente de várias formas, muitos desses problemas podem ser irreversíveis.

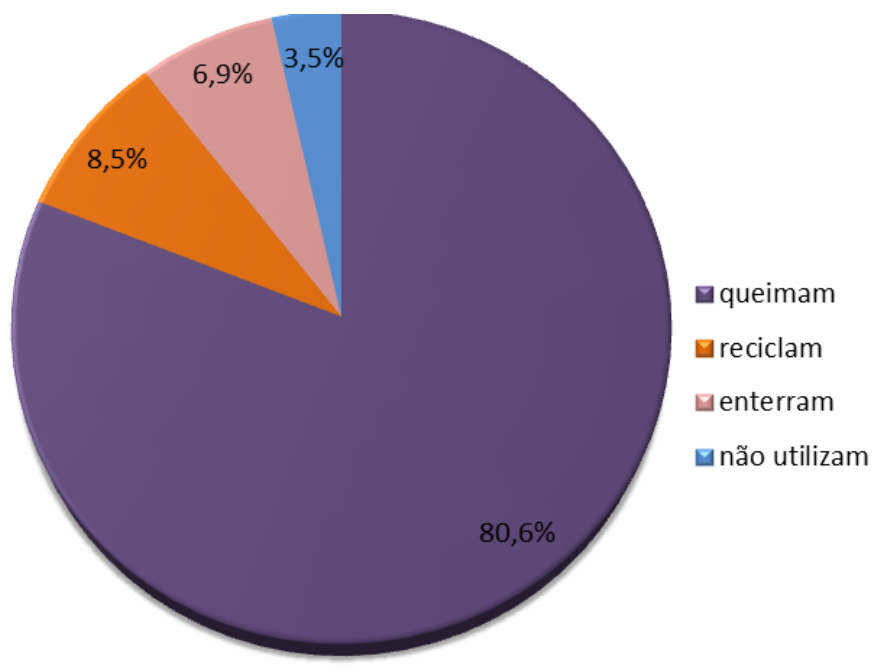

Figura 8- Percentual do tipo de manuseio do lixo doméstico da Unidade Escolar Felipe Neris Machado, Caxigó, PI. (CRUZ, 2014). 


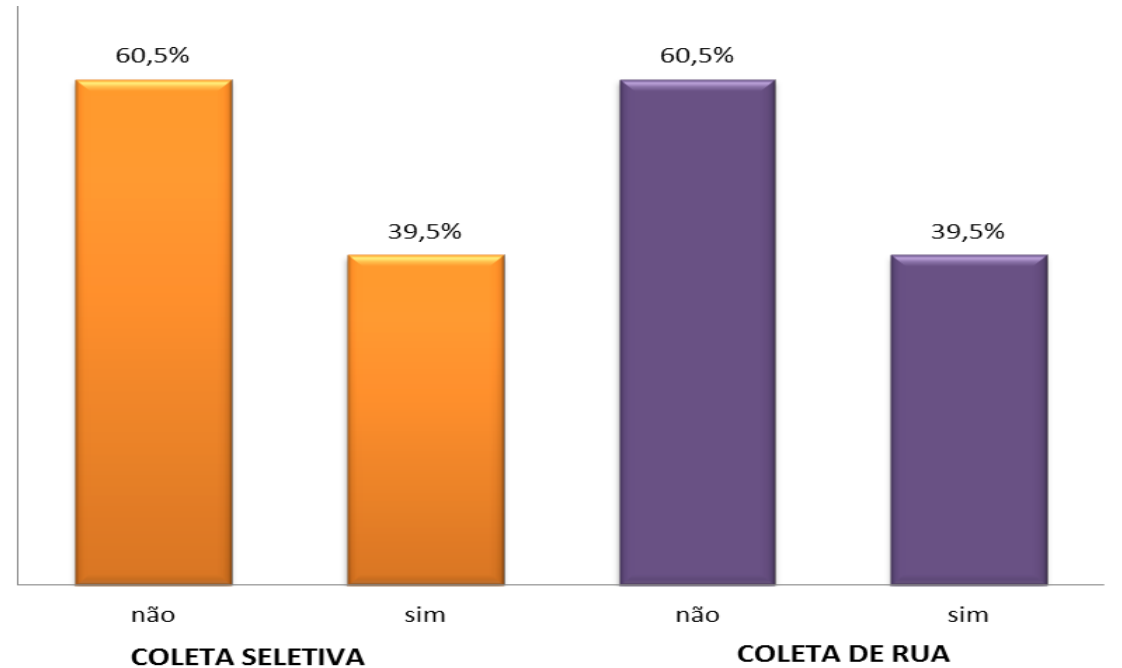

Figura 9- Percentual relacionado à coleta do lixo na rua ou localidade da Unidade Escolar Felipe Neris Machado, Caxingó, PI. (Fonte: CRUZ, 2014).

Questão 16- Sobre a importância da preservação do meio ambiente, a maioria (98,4\%), considera importante enquanto $1,6 \%$ responderam que preservação do meio ambiente não tem importância.

Pelas respostas obtidas, pode-se perceber que existe consciência nos alunos em preservar o meio ambiente. Dados semelhantes foram encontrados por, Machado et al. (2010) em escola do Distrito de Luzimangues Porto Nacional, TO.

Etimologicamente, preservar e conservar tem o mesmo sentido, entretanto, conservar é permitir a exploração econômica dos recursos naturais de maneira racional e sem causar danos no ambiente, enquanto preservar é proibir exploração econômica de seus recursos. A sustentabilidade, por sua vez, concilia a necessidade de preservar com a necessidade de incentivar o desenvolvimento socioeconômico. Sustentabilidade também pode ser denominada de desenvolvimento ecologicamente equilibrado, desenvolvimento sustentado ou sustentável e eco desenvolvimento (SIRVINSKAS, 2003).

Questão 17 - Verificou o que os alunos têm feito para a melhoria do ambiente em que vivem, utilização de materiais biodegradáveis, não jogar lixo em local indevido, não poluir o ar, rios, lagos; participam de algum projeto socioambiental e outros. A maioria dos questionados $(68,2 \%)$ respondeu que não jogam lixo em local indevido, não polui o ar, rios, lagos $(26,4 \%)$ e utilizam materiais biodegradáveis (5,4\%) (Fig.10).

A porcentagem relacionada a não jogar lixo no meio ambiente $(68,2 \%)$ corrobora com Arruda (2011) em estudo realizado em escolas de Parnaíba-PI como a Escola Municipal Dr. Cândido Athayde; 86,7\%na Unidade Escolar Janete Souza; e 72,7\% Unidade Escolar Professor Augusto Lopes. A resposta dos questionados foi que o ambiente melhora quando se joga menos lixo no chão $81,5 \%$.

O estudo da percepção nas relações ser humano-ambiente pode favorecer um uso mais sustentável dos recursos ambientais (MALAFAIA; RODRIGUES, 2009). Diante das respostas do alunado pode-se perceber que há uma preocupação dos alunos em preservar o meio ambiente através de ações que demonstraram exercer no local em que residem. Mas ainda há muito a ser feito para mudar a realidade da cidade e no mundo. 


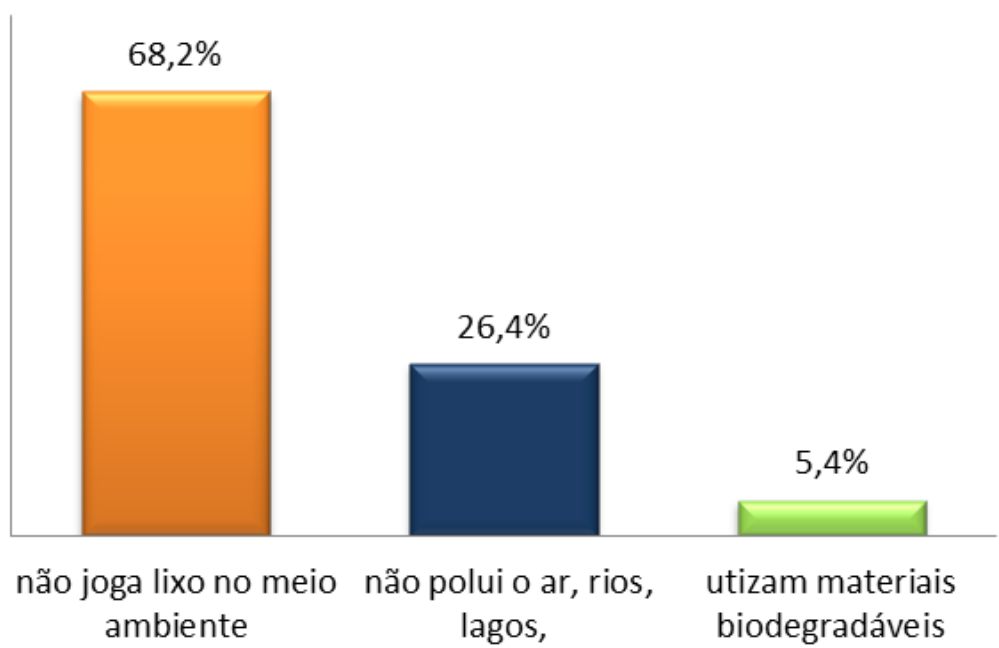

Figura 10- Porcentagem das ações dos alunos da Unidade Escolar Felipe Neris Machado, Caxingó, PI para melhoria do ambiente em que vivem.

\section{CONSIDERAÇÕES FINAIS}

A percepção ambiental dos alunos é pouco elaborada, reforçando a necessidade de um desenvolvimento maior sobre o tema Educação Ambiental no cotidiano escolar. O município de Caxingó necessita de um programa em Educação Ambiental para que a população Caxingoense esteja mais informada a respeito dos danos causados ao meio ambiente.

A escola precisa de um programa de Educação Ambiental que esteja inserido no quadro de disciplinas obrigatórias ofertadas ao alunado, pois há uma carência em atividades direcionadas a mesma.

Os principais problemas ambientais identificados pelos alunos foram: falta de abastecimento de água tratada nas residências, saneamento básico, manuseio do lixo de forma correta, queimadas e desmatamento e principalmente um programa de conscientização. A falta desses recursos para a população local pode ocasionar vários problemas e danos à saúde tornando o ambiente propício a alguns vetores transmissores de doenças.

O Município necessita de serviços de coleta de lixo e tratamento adequados dos resíduos e dejetos produzidos na região. Falta política voltada à Educação Ambiental que promova uma conscientização da população em conservar, ou seja, utilizar os recursos disponíveis na natureza de forma adequada e sustentável sem causar danos irreversíveis ao planeta.

Acredita-se que através do ambiente escolar é possível disseminar a importância da conservação do ambiente para as gerações presentes e futuras. E somente será possível controlar os problemas presentes no meio ambiente através de trabalho conjunto entre orgãos competentes e sociedade em geral.

\section{REFERÊNCIAS BIBLIOGRÁFICAS}

1. ANDRADE, H. IBGE aponta que distribuição de água cresceu em todas as regiões do Brasil. Disponível em: <http://noticias.uol.com.br/cotidiano/ultimas-noticias/2011/04/29/ibgeaponta-que-distribuicao-de-agua-cresceu-em-todas-as-regioes-do-brasil.htm>. Acesso em 
25.fev.2014.

2. ARRUDA, E. M. Níveis de Consciência dos Alunos do Ensino Fundamental de escolas públicas do município de Parnaíba-Pi. 56f. Monografia apresentada como requisito para obtenção de grau em licenciatura plena em Biologia, Universidade Federal do Piauí-UFPI, Campus Ministro Reis Velloso-CMRV. Parnaíba, 2011.

3. ANDRADES, E. O. Percepção dos alunos da rede pública de ensino sobre a questão ambiental do município de Parnaíba, Piauí. 2010. Monografia apresentada como requisito para obtenção de grau em licenciatura plena em Biologia, Universidade Federal do Piauí-UFPI, Campus Ministro Reis Velloso-CMRV. Parnaíba, 2010.

4. BEZERRA, T. M. O.; GONÇALVES, A. A. C. Concepções de meio ambiente e educação ambiental por professores da Escola Agrotécnica Federal de Vitória de Santo Antão-PE. Biotemas, v. 20, n. 3, p. 115-125. 2007.

5. BORGES, J. G; MATOS. M.M. Manual Básico de Educação Ambiental. 1. ed. São Paulo:1990.

6. BRASIL. Secretaria de Educação Fundamental. Parâmetros curriculares nacionais: ciências naturais/Secretaria de Educação Fundamental- Brasília: MEC/SEF, 1997.136p. CARVALHO, I. C. M. Educação ambiental: a formação do sujeito ecológico. 2. ed. São Paulo: Cortez, 2006.

7. DIAS, G. F. Educação Ambiental: Princípios e Práticas. 8. ed. São Paulo: Gaia, 2003. 551p.

8. DOURADO, L. F. Fracasso escolar no Brasil: Políticas, programas e estratégias de prevenção ao fracasso escolar. Brasília, 2005.

9. EFFTING, T. R. Educação Ambiental nas Escolas Públicas: Realidade e Desafios . Marechal Cândido Rondon, 2007. Monografia (Pós Graduação em "Latu Sensu" lanejamento Para o Desenvolvimento Sustentável) - Centro de Ciências Agrárias, Universidade Estadual do Oeste do Paraná - Campus de Marechal Cândido Rondon, 2007.

10. FERREIRA, M. R. Produção e conhecimento sobre degradação ambiental: uma incursão na psicologia ambiental. 1997. Tese (Doutorado em Psicologia Social). Pontifícia Universidade Católica, São Paulo-1997.

11. FURTADO, Eliane D. P. Estudo sobre a população rural no Brasil. In: FAO, UNESCO; CIDE/REDUC. Educación para la población rural en Brasil, Chile, Colombia, Honduras, México, Paraguay y Perú . Santiago: UNESCO; FAO, 2004, p. 45-91.

12. GALLO, S. Transversalidade e meio ambiente. Ciclo de palestras sobre meio ambiente. Secretaria de Educação Fundamental - Brasília: MEC; SEF, 2001. p. 56.

13. IBGE - Instituto Brasileiro de Geografia e Estatística. Cidades: Caxingó. Disponível em:<http://cidades.ibge.gov.br/xtras/perfil.php?lang=\&codmun=220265\&search=piaui | caxi ngo. Acesso em:06.11.2013.

14. IBGE. Instituto Brasileiro de Geografia e Estatística - IBGE. Pesquisa Nacional de Saneamento Básico 2008. Rio de Janeiro: IBGE, 2010.

15. JACOBI. P. Educação Ambiental, Cidadania e Sustentabilidade. Cadernos de Pesquisa, n. 118, março/ 2003.

16. LOPES. W.; BISPO. W.; CARVALHO. J. Educação Ambiental nas Escolas: Uma Estratégia de Mudança Efetiva. Palmas-TO, 2009.

17. LOPEZ, T. M.; ZANCUL. M. C. S. Educação Ambiental nos Anos Finais do Ensino Fundamental 
em uma escola do Campo: Uma Análise a Partir do Projeto Político Pedagógico. Ensino, Saúde e Ambiente - v.5, n.2, pp. 211-221, ago. 2012.

18. LORENZI, G. M. A. Educação Ambiental: Educar ou Informar? 2003. Disponível em: <http://ojs.c3sl.ufpr.br/ojs2/index. php/acadêmica/article/download/533/446>. Acesso em: 12.10.13.

19. LOUREIRO, C. F. B. Educação Ambiental Crítica: contribuições e desafios. Brasília, 2007.

20. MACHADO. A. S.; GONÇALVES. D. M.; CARDOSO. J. R.; WEISS. V. A. B.; SANTOS. A. B. A.; Educação Ambiental de 6o a 9o ano: Um Estudo na Escola Estadual Beira Rio do Distrito de Luzimangues Porto Nacional - Tocantins, 2010.

21. MALAFAIA, G.; RODRIGUES, A. S. L. Percepção ambiental de jovens e adultos de uma escola municipal de ensino fundamental. Revista Brasileira de Biociências, Porto Alegre, v. 7, n. 3, p. 266-274, jul./set. 2009.

22. MARCONI, M. A.; LAKATOS, E. M. Fundamentos de metodologia científica. São Paulo: Atlas, 2011, $315 \mathrm{p}$.

23. OlIVEIRA, F. M.; MONTEIRO, M. S. L. Água para todos: Um desafio para o desenvolvimento sustentável. In: VI Encontro da Sociedade Brasileira de Economia Ecológica (ECOECO). Brasília. 2005, 16p.

24. PALMA, I.R. Análise da Percepção Ambiental como Instrumento ao Planejamento da Educação Ambiental. 2005. 67p.

25. PNRS. Plano Nacional de Resíduos Sólidos. Brasilia. 2012. Disponível em: http://www.mma.gov.br/port/conama/reuniao/dir1529/PNRS_consultaspublicas.pdf. Acesso em: 07.jan. 2014.

26. PORTELA, G. L. Abordagens teórico-metodológicas. Projeto de Pesquisa no ensino de Letras para o Curso de Formação de Professores da UEFS. 2004.

27. ROCHA. A. P. A Educação Ambiental no Contexto Escolar como Elemento Indispensável para Transformação da Consciência Ambiental. Monografia apresentada ao Instituto Superior de Educação da Faculdade Alfredo Nasser, como parte dos requisitos para a conclusão do curso de Pedagogia. Aparecida de Goiânia-2010.

28. SANTOS, E. T. A. Educação Ambiental na Escola: Conscientização da Necessidade de Proteção da Camada de Ozônio. Santa Maria, RS, Brasil, 2007.

29. SARAIVA, V. M.; NASCIMENTO, K. R .P; COSTA, R. K. M. A prática pedagógica do ensino de educação ambiental nas escolas públicas de João Câmara - RN. 2008

30. SEMEC, Secretaria Municipal de Educação e Cultura. Caxingó-PI. 2013.

31. SORRETINO, M. et al. Educação ambiental como política pública. 2005.

32. TOZONI-REIS, M. F. C.. Educação Ambiental: natureza, razão e história. 2a ed. Rev. Campinas, SP:Autores Associados, 2008. 167p.

33. TUAN, Y. Topofolia: um estudo da percepção, atitudes e valores do meio ambiente. Trad. Lívia de Oliveira. São Paulo: DIFEL, 1980. 